\title{
THE PLASMA FATS AND THE IODINE ABSORPTION CAPACITY OF THE FATTY ACIDS IN HYPERTHYROIDISM
}

By ELIZABETH G. NICHOLLS and WILliaM A. PERLZWEIG

(From the Chemical Division of the Medical Clinic of the Johns Hopkins University and Hospital, Baltimore)

(Received for publication November 8, 1927)

A diminution in the surface tension of the blood serum has been found in many cases of hyperthyroidism as reported in a previous paper (1). Since it is well known that the unsaturated fatty acids are highly surface active, we have investigated the amount of these substances in relation to the plasma fats as a possible cause of the above observed phenomenon in patients with this disease. The blood fats in a short series of normal persons studied at the same time as a basis for comparison.

Sixteen cases of hyperthyroidism and exophthalmic goitre have been studied. The blood was collected shortly after the patient was admitted to the ward and before the administration of iodine was commenced. Determinations were again made when the therapeutic effect of the iodine administered was considered to be at its maximum, and still later after surgical operation.

Iodine was administered in the form of Lugol's solution, the usual dosage being 30 minims daily. In many cases the administration of Lugol's solution was continued for a short period after operation in dosage of 5 to 10 minims daily. The patients were given no food for at least sixteen hours before collection of the blood for study. The basal metabolic rate was determined when possible the same day that the blood was taken, and also at frequent intervals thereafter.

Extensive studies have been made by Bloor, Leathes, Czonka and others $(3,4,5)$ upon the fatty acids of normal blood plasma. The methods which we have employed in the studies here reported are as follows: 


\section{METHODS OF ANALYSIS}

The total fats were determined in oxalated plasma or serum by the titrimetric method of Stewart and White (6) which was modified as follows: The plasma (5 to $8 \mathrm{cc}$.) was measured into about 18 volumes of a 3:1 alcohol-ether mixture drop by drop, and heated to boiling in a hot water bath with rotation. It was then cooled, filtered, and made up to a definite volume with the alcohol-ether mixture, including the washings of the protein coagulum on the filter. Aliquots of the extract, in duplicate, representing 1 to $2 \mathrm{cc}$. of the plasma were placed into $60 \mathrm{cc}$. Florence flasks of pyrex or Nonsol glass. Five cubic centimeters of $\mathrm{N} / 10 \mathrm{NaOH}$ were added from a calibrated pipette or micro-burette, and the mixture slowly saponified on a moderately hot steam bath for about 2 hours until almost dry. It was found that at this point saponification of the neutral fats was not invariably complete as is claimed by the authors of this method. However, in every case complete saponification was effected by the addition of $5 \mathrm{cc}$. of absolute alcohol, with subsequent boiling and continued evaporation on the steam bath for a further period of an hour or more. The fatty acids of the soaps were now liberated by the addition of accurately measured $5 \mathrm{cc} . \mathrm{N} / 10 \mathrm{HCl}$. The contents of the flask were boiled down on a free flame to about $1 \mathrm{cc}$., $10 \mathrm{cc}$. of absolute alcohol and two drops of a 0.5 per cent phenolphthalein in 50 per cent alcohol were added, and the solution brought to boiling. The final titration with carbon dioxide free $\mathrm{N} / 10 \mathrm{NaOH}$ was then carried out with a burette graduated in $0.02 \mathrm{cc}$. divisions and provided with a fine tip. The titration was carried on to a light pink color which persisted for at least one minute. Each set of determinations was accompanied by two or three blank determinations on the reagents alone, and the blank figures were subtracted from the final titration. Frequent checks with solutions of pure tripalmitin, triolein and tributyrin, and with mixtures of these fatty acids were performed, and these determinations convinced us that the simple method as outlined above yielded results which were accurate within 5 per cent of the theoretical values. The chief advantages of this modification over the original method are in the certainty of more complete saponification of the fat, in the use of larger samples of material and in obviating the use of the Rehberg microburette which is difficult to obtain and to manipulate. By this method the analyses yield figures which include the free fatty acids, and the acids combined in the neutral fats, soaps, cholesterol esters and in the phosphatids. The figures or total fat given in the tables were calculated in terms of tripalmitin and are therefore not strictly comparable with figures obtained by the use of other methods involving the weighing of the total soluble fat or by means of nephlometric comparison against an arbitrary standard of a mixture of fatty acids.

The iodine number of the fat was determined in the alcohol ether extracts by the admirable microadaptation of the well known Hanus method described by Gibson and Howard (7) and used by these authors for the determination of the iodine number of the blood fats in pernicious anemia. In tables 1 and 2 the iodine 
figures are given in two columns. In the first column are shown the grams of iodine absorbed by 100 grams of fat.

Cholesterol determinations were made from the same alcohol-ether extract as the fats according to Sackett's (8) modification of Bloor's method for the determination of cholesterol in whole blood and serum.

The basal metabolic rate was determined by means of the Benedict Roth apparatus by the routine procedure employed in this hospital.

In table 1 are presented the results obtained for the total fatty acids, the iodine absorption and the iodine number in eleven normal individuals. In the group which was studied during a fasting period, the blood was collected before breakfast, at least 16 hours after the previous meal. In four of these the blood was collected both fasting and again $2 \frac{1}{2}$ to 3 hours after a moderate lunch. The second group gives the figures for blood collected at various times after eating.

As will be observed, quite constant figures were obtained for the fasting state. The total fat of the plasma varied between 333 and $492 \mathrm{mgm}$. per cent, average $426 \mathrm{mgm}$. per cent. The iodine absorbed varied from 316 to $412 \mathrm{mgm}$. per cent, average $351 \mathrm{mgm}$.; while the iodine number of the fat varied between 66 and 104, average 84 . Remarkable constancy was found for any given individual on whose blood analyses were repeated on different days. With the ingestion of ordinary mixed food it was found, as expected, that in 1 to $3 \frac{1}{2}$ hours the concentration of the total fat of the blood had risen greatly to an average of 51 per cent above the fasting average. The iodine absorbed per $100 \mathrm{cc}$. plasma rose 23 per cent higher, while the iodine number (degree of unsaturation) of the fatty acids had fallen 18 per cent of the fasting average. This seems to indicate that the postprandial increase in the blood fat is chiefly accounted for by the saturated fatty acids.

In table 2 are presented data upon sixteen patients in various stages of thyroid intoxication. Most of these, as far as could be determined, were not given any special treatment or medication before our study began. The exceptions are recorded in the last column under "Remarks." It will be noted that in 13 of these cases the initial plasma fat concentration is considerably lower than in the normal subjects, varying from 123 to $307 \mathrm{mgm}$. per cent. This low plasma fat is in every case associated with a high iodine number, but the 
amount of iodine absorbed per $100 \mathrm{cc}$. of plasma appears to be within our normal range. It seems, therefore, that the absolute concentra-

TABLE 1

Total fatty acid concentration (as tripalmitin) and iodine number in blood plasma from normal individuals

\begin{tabular}{|c|c|c|c|c|c|c|}
\hline Subject & Date & & $\begin{array}{l}\text { Total } \\
\text { fatty } \\
\text { acids }\end{array}$ & $\begin{array}{c}\text { Iodine } \\
\text { absorbed }\end{array}$ & $\left|\begin{array}{c}\text { Iodine } \\
\text { num- } \\
\text { ber }\end{array}\right|$ & Remarks \\
\hline \multicolumn{7}{|c|}{ Fasting } \\
\hline \multirow{4}{*}{ E. N..... } & & & $\begin{array}{c}\text { grams } \\
\text { tripal- } \\
\text { mitin per } \\
\text { 100 cc. } \\
\text { plasma }\end{array}$ & $\begin{array}{l}\text { grams } \\
\text { per } \\
100 \text { ce. } \\
\text { plasma }\end{array}$ & & \\
\hline & November & & 0.338 & 0.365 & 107 & \\
\hline & December 3 & & 0.333 & 0.357 & 98 & \\
\hline & January 2 & & 0.355 & 0.370 & $104^{*}$ & \\
\hline & December 3 & & 0.487 & 0.327 & 67 & \\
\hline & January 3 & 31 & 0.492 & 0.341 & $69^{*}$ & \\
\hline L. F. & January & 31 & 0.492 & 0.381 & $77^{*}$ & \\
\hline F. H. & January & 31 & 0.369 & 0.316 & $86^{*}$ & \\
\hline & February & 12 & 0.446 & 0.408 & 92 & \\
\hline & January & 16 & 0.458 & 0.412 & 90 & \\
\hline M. G. & January & 31 & 0.338 & 0.327 & 97 & \\
\hline I. $\mathrm{W}$. & January & 31 & 0.492 & 0.326 & 66 & \\
\hline \multicolumn{3}{|l|}{ Average. } & 0.426 & 0.351 & 84 & Fasting \\
\hline \multicolumn{7}{|c|}{ Not fasting } \\
\hline E. N.. & January & 24 & 0.556 & 0.369 & 66 & 2.5 hours after moderate meal \\
\hline F. B.. & January & 31 & 0.860 & 0.390 & 45 & 3 hours after moderate meal \\
\hline I. F. . & January & 31 & 0.630 & 0.419 & 66 & 3 hours after heavy meal \\
\hline F. H.. & January & 31 & 0.557 & 0.381 & 68 & 3 hours after heavy meal \\
\hline W.P. & December & 2 & 0.634 & 0.440 & 69 & 2.5 hours after light breakfast \\
\hline T. C.. & December & 6 & 0.554 & 0.526 & 95 & 3.5 hours after light lunch \\
\hline E. B.. & December & 2 & 0.846 & 0.622 & 73 & 1.2 hours after heavy meal \\
\hline D.D. . & December & 6 & 0.492 & 0.365 & 74 & 1 hour after light lunch \\
\hline \multicolumn{3}{|c|}{ Average $\ldots \ldots \ldots \ldots \ldots \ldots$} & 0.641 & 0.434 & 69.5 & Non-fasting \\
\hline
\end{tabular}

* Repeated same day after taking food (see below in this table).

tion of the unsaturated fatty acids is not increased in these cases, and that both the lowering of the total fat and the high iodine number of the plasma fat are due to a deficit in the saturated fatty acid radicals. 
Under iodine therapy, with or without operation, the total plasma fat rises remarkably, often to a concentration much higher than that found in fasting normal subjects. That the rise in plasma fats under this treatment is due largely to an increase in the saturated rather than the unsaturated fats, is again shown by a sharp drop in the iodine number of the fat, while the absolute amount of iodine absorbed per $100 \mathrm{cc}$. plasma remains approximately constant or even rises in some cases. Jobling and Petersen (8), citing older literature, pointed out some years ago that the administration of iodides tends to saturate the unsaturated fatty acids and thus destroy their antitryptic property. If such saturation or oxidation of the unsaturated fatty acids occurred in our hyperthyroid cases, it must have taken place but to a slight extent, for the absolute amount of iodine absorbed per $100 \mathrm{cc}$. of plasma did not decrease. The increase in the total fatty acids in the circulating blood was, as pointed out above, due to an accretion of saturated fatty acids.

The cholesterol determinations indicated low values in the more severe cases of hyperthyroidism and a definite increase towards the normal or slightly above the normal range as symptoms improved. The increase appears to parallel the increase in the saturated fatty acids. Low figures for the blood cholesterol have been reported by Dennis (10) in four cases of severe hyperthyroidism and figures within normal limits in four mild cases. No consecutive figures throughout the course of the treatment were given, and no data are given upon which to judge of the severity of the disease or of the exact diagnosis. Epstein and Lande (11) published in 1922 an interesting series of figures showing an inverse relationship between the basal metabolic rate and the cholesterol level in the blood in certain conditions. Low cholesterol figures are reported in cases of exophthalmic goitre and toxic thyroid adenomas. On the other hand in a series of cases with subnormal basal metabolism, including myxedema and nephrosis, high blood cholesterol figures were found. Thyroid therapy in some of these latter cases as well as in two cases of nephrosis recently reported by Liu (12), resulted in a lowering of the blood cholesterol as the basal metabolic rate came down and the clinical symptoms improwed. 


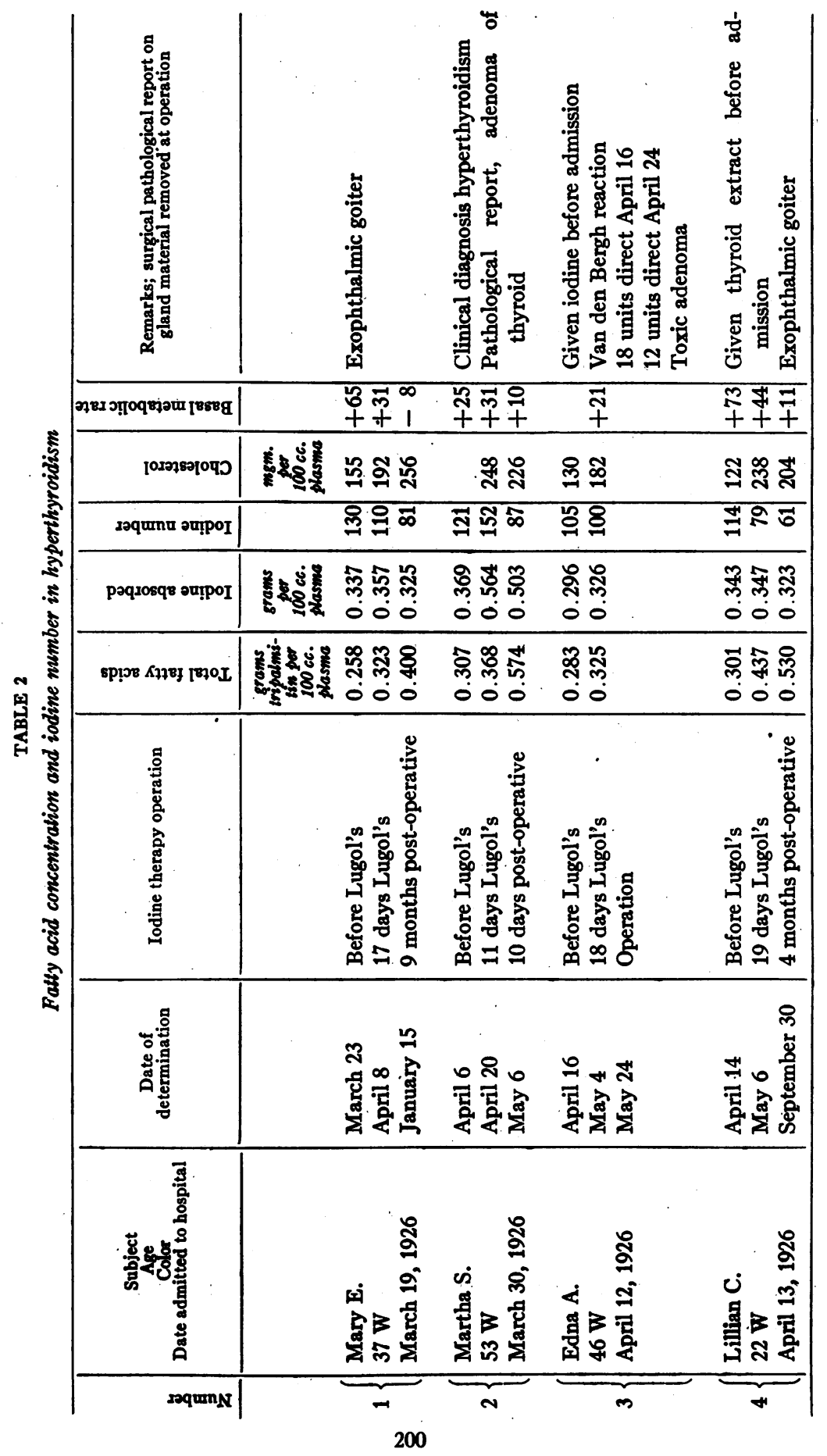




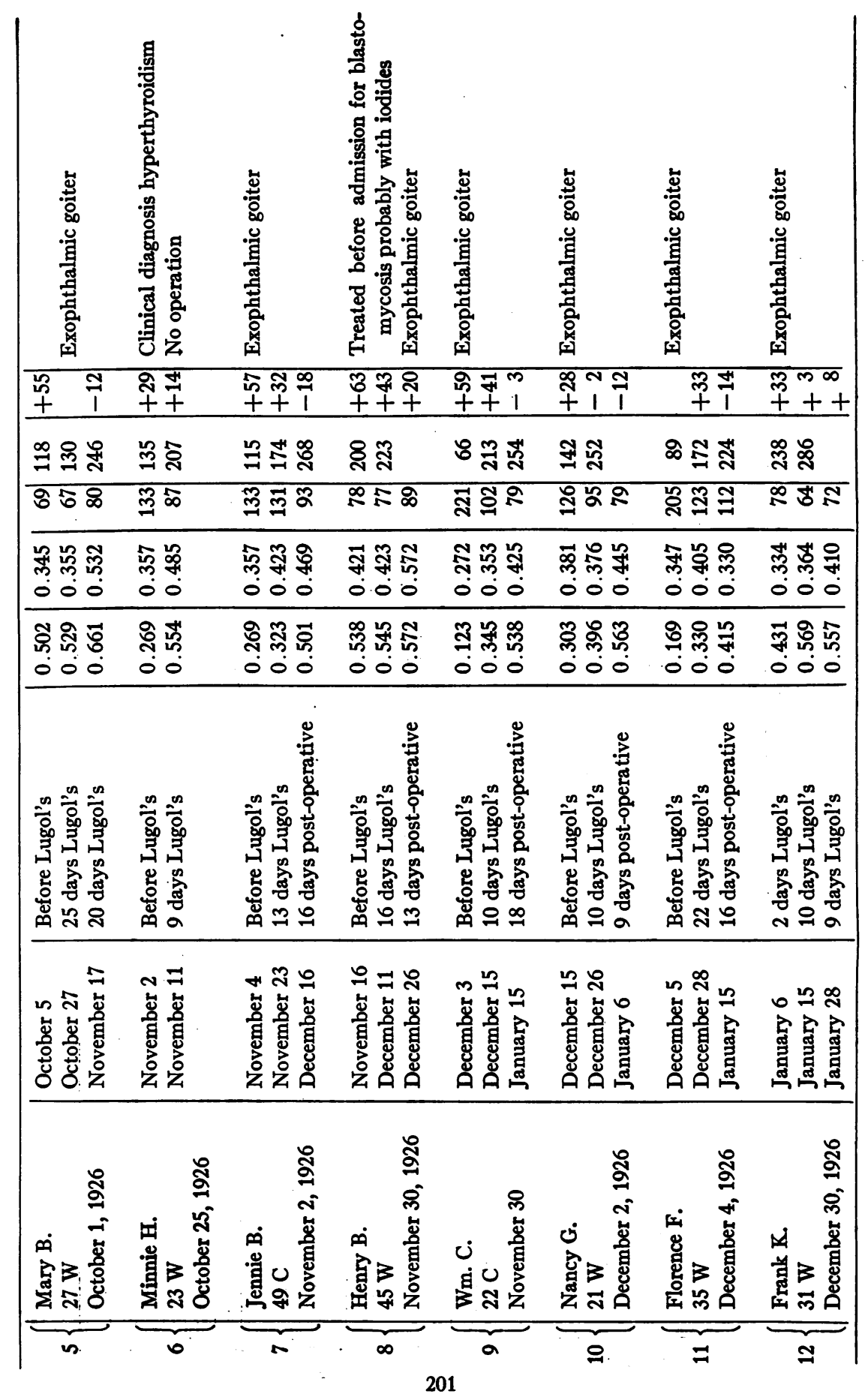




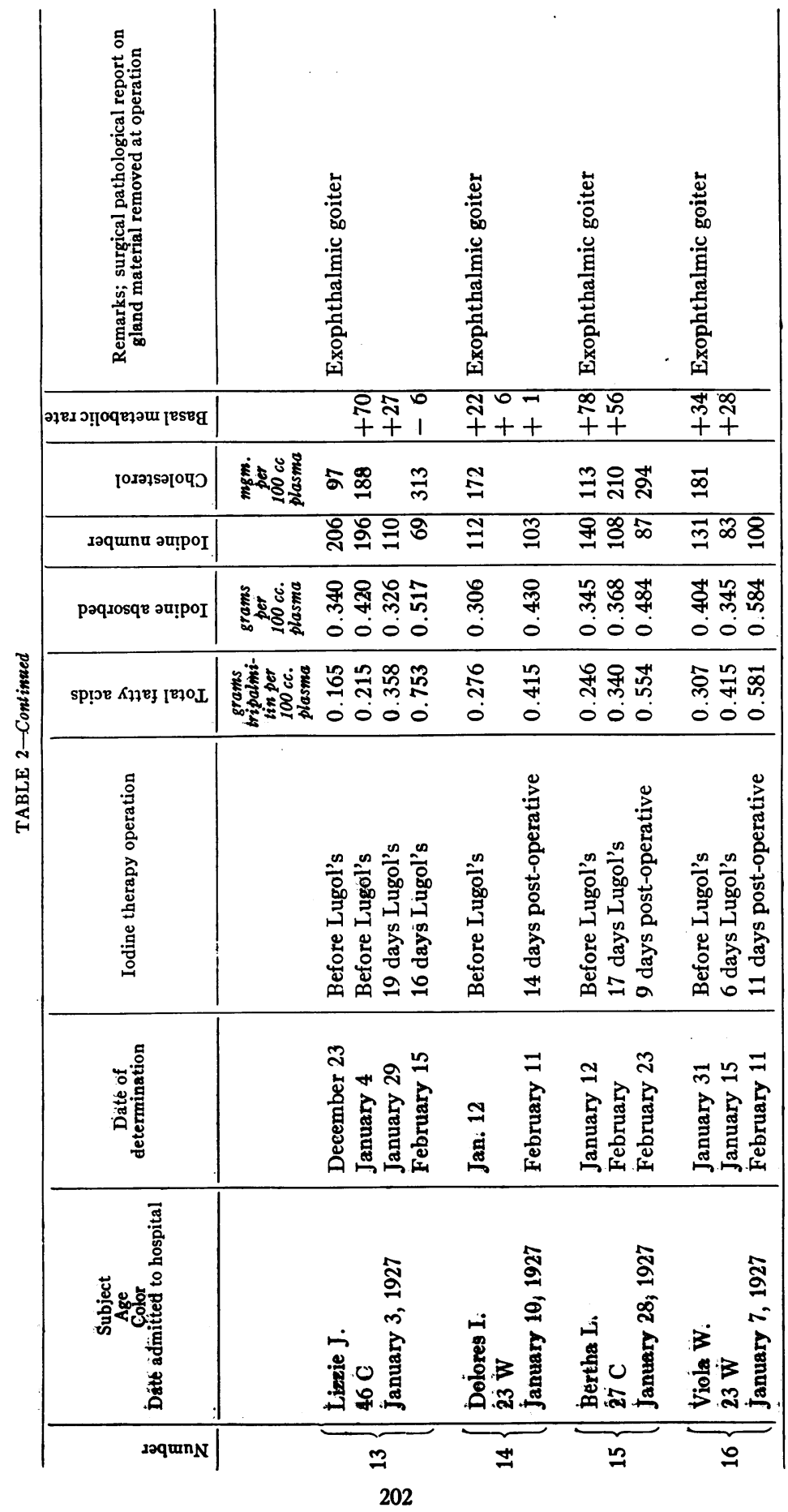


These observations upon the fatty acids and cholesterol indicate that significant changes in fat metabolism occur under iodine therapy in cases of thyroid intoxication. In general the data in table 2 show that the increase in the blood fat accompanies the lowering in the basal metabolic rate and the clinical improvement. Beyond the fact that the surface tension of the blood serum is definitely lowered in hyperthyroid disease (1) there does not. appear to be any obvious parallelism between it and the fat figures presented. The surface tension often remains low after iodine therapy even when the fats have returned to a normal level.

\section{SUMMARY}

Data are presented on the distribution of the fatty acids and their relative degree of unsaturation (iodine number) in the blood plasma of eleven normal individuals and in sixteen cases of hyperthyroid disease before and after iodine therapy.

The total fatty acids of the plasma are markedly decreased in the untreated cases and the iodine number of these acids is greatly increased. These changes appear to be due not to an increase in the unsaturated fatty acids but to a decrease in the saturated acids.

Under iodine treatment and after operation, coincident with the lowering of the basal metabolic rate, the total fat rises and the iodine number drops to normal because of an absolute increase in the saturated fat content of the plasma.

The cholesterol content of the plasma is low in the more severe cases of hyperthyroid intoxication. It rises with the increase of the saturated fatty acids as the clinical symptoms improve, and the basal metabolic rate returns to normal under iodine treatment and operation.

The writers wish to acknowledge the help of Miss Beulah Schaub in the determination of the basal metabolic rates.

\section{BIBLOGRAPHY}

1. Nicholls, E. G., and Harrop, G. A., J. Clin. Invest. 1928, v. 181. The Surface Tension of the Blood Serum in Hyperthyroidism.

2. Wilhelmj, C. M., and Fleisher, M. S., J. Exper. Med., 1926, xliii, 179 and 195. The Relation of the Thyroid Gland to the Surface Tension of the Blood Plasma. 
3. Bloor, W. R., J. Biol. Chem., 1923, lvi, 711. The Fatty Acids of Blood Plasma. Chem. Reviews, 1926, ii, 243. Biochemistry of the Fats.

4. Leathes, J. B., and Raper H. S., Biochem. Monographs, 1925, iv, 213. The Fats.

5. Csonka, F. A., J. Biol. Chem., 1918, xxxiii, 401. The Fatty Acids in Human Blood in Normal and Pathological Conditions.

6. Stewart, C. P., and White, A. C., Biochem. Jour., 1925, xix, 841. The Estimation of Fat in Blood.

7. Gibson, R. B., and Howard, C. P., Arch. Int. Med., 1923, xxxii, 1. Metabolic Studies in Pernicious Anemia.

8. Sackett, G. E., J. Biol. Chem., 1925, lxiv, 203. Modification of Bloor's Method for the Determination of Cholesterol in Whole Blood or Blood Serum.

9. Jobling, J. W., and Petersen, W., J. Exper. Med., 1914, xix, 459. The Nature of Serum Antitrypsin. Studies on Ferment Action. XIII.

10. Denis, W., J. Biol. Chem., 1917, xxix, 93. Cholesterol in Human Blood under Pathological Conditions.

11. Epstein, A. A., and Lande, H., Arch. Int. Med., 1922, xxx, 563; and Medical Record, 1921, c, 1096. The Relation of Cholesterol and Protein Deficiency to Basal Metabolism.

12. Liu, S., Arch. Int. Med., 1927, xl, 73. The Effect of Thyroid Medication in Nephrosis. 